\title{
Os benefícios ambientais do plantio de eucalipto: revisão de literatura
}

\author{
The environmental benefits of eucalyptus planting: literature review
}

Los beneficios ambientales de la plantación de eucalipto: revisión de la literatura

\section{Resumo}

Em 2019, as florestas plantadas totalizaram 9,0 milhões de hectares, aumento de 2,4\% em relação a 2018. Desse total, a maior parte (77\%) é representada pelo eucalipto, com cerca de 6,97 milhões de hectares, e 18\% de pinus, com 1,64 milhão de hectares. Os plantios de eucalipto tem uma grande aceitação no Brasil devido seu rápido crescimento, alta produtividade, seus múltiplos produtos (papel, celulose, móveis, painéis de madeira, pisos, carvão, construção civil) e também está relacionado com a lucratividade gerada pelo mesmo. Mas, apesar de todos esses fatores positivos do seu plantio, ainda assim existem muitos mitos relacionados aos impactos negativos gerados ao meio ambiente advindos do eucalipto. Nesse contexto, a pesquisa teve como objetivo salientar os impactos ambientais positivos de plantios de eucalipto observando sua influência sobre o solo, água, proteção de florestas nativas, ciclagem de nutrientes e fixação de carbono. Para isso foi realizada uma revisão narrativa de literatura e como critério de inclusão, foram considerados artigos científicos, revistas, periódicos, gratuitamente e na íntegra, no idioma português, espanhol e inglês. Comparando o eucalipto com outras culturas agrícolas e florestais foi constatado que seu plantio é o que menos consume água e retém nutrientes. Verificou-se consenso na literatura a cerca dos impactos benéficos do plantio do eucalipto sobre o solo protegendo contra erosões hídricas, água, proteção de matas nativas e reter grandes quantidades de $\mathrm{CO}_{2}$ da atmosfera melhorando a qualidade do ar.

Palavras-chave: Florestas plantadas; Proteção; Silvicultura.

\begin{abstract}
In 2019, planted forests totaled 9.0 million hectares, an increase of $2.4 \%$ compared to 2018 . Of this total, the majority $(77 \%)$ is represented by eucalyptus, with about 6.97 million hectares, and $18 \%$ of pine, with 1.64 million hectares. Eucalyptus plantations are widely accepted in Brazil due to their rapid growth, high productivity, their multiple products (paper, cellulose, furniture, wood panels, floors, charcoal, civil construction) and is also related to the profitability generated by it. But, despite all these positive factors of its planting, there are still many myths related to the negative impacts generated by eucalyptus on the environment. In this context, the research aimed to highlight the positive environmental impacts of eucalyptus plantations, observing their influence on soil, water, protection of native forests, nutrient cycling and carbon fixation. For this, a narrative literature review was carried out and, as an inclusion criterion, scientific articles, journals, periodicals were considered, free of charge and in full, in Portuguese, Spanish and English. Comparing eucalyptus with other agricultural and forestry crops, it was found that its planting consumes less water and retains nutrients. There was a consensus in the literature about the beneficial impacts of planting eucalyptus on the soil,
\end{abstract}


protecting against erosion by water, water, protection of native forests and retaining large amounts of $\mathrm{CO}_{2}$ from the atmosphere, improving air quality.

Keywords: Planted forests; Protection; Silviculture.

\begin{abstract}
Resumen
En 2019, los bosques plantados totalizaron 9,0 millones de hectáreas, un aumento del 2,4\% con respecto a 2018. De este total, la mayoría (77\%) está representada por eucaliptos, con alrededor de 6,97 millones de hectáreas, y el 18\% de pino, con 1,64 millones de hectáreas. . Las plantaciones de eucalipto son ampliamente aceptadas en Brasil debido a su rápido crecimiento, alta productividad, sus múltiples productos (papel, celulosa, muebles, paneles de madera, pisos, carbón vegetal, construcción civil) y también está relacionado con la rentabilidad que genera. Pero, a pesar de todos estos factores positivos de su plantación, aún existen muchos mitos relacionados con los impactos negativos que genera el eucalipto sobre el medio ambiente. En este contexto, la investigación tuvo como objetivo resaltar los impactos ambientales positivos de las plantaciones de eucalipto, observando su influencia en el suelo, el agua, la protección de los bosques nativos, el ciclo de nutrientes y la fijación de carbono. Para ello, se realizó una revisión de literatura narrativa y, como criterio de inclusión, se consideraron artículos científicos, revistas, publicaciones periódicas, de forma gratuita y en su totalidad, en portugués, español e inglés. Al comparar el eucalipto con otros cultivos agrícolas y forestales, se encontró que su plantación consume menos agua y retiene nutrientes. Hubo consenso en la literatura sobre los impactos beneficiosos de plantar eucaliptos en el suelo, protegiendo contra la erosión por agua, protección de los bosques nativos y reteniendo grandes cantidades de $\mathrm{CO}_{2}$ de la atmósfera, mejorando la calidad del aire.
\end{abstract}

Palabras clave: Bosques plantados; Proteccion; Silvicultura.

\title{
1. Introdução
}

Em 2019, as florestas plantadas totalizaram 9,0 milhões de hectares, aumento de 2,4\% em relação a 2018 (8,79 milhões de hectares, considerando o ajuste conforme nova metodologia). Desse total, a maior parte (77\%) é representada pelo eucalipto, com cerca de 6,97 milhões de hectares, e 18\% de pinus, com 1,64 milhão de hectares. (IBÁ, 2020). Os plantios de eucalipto estão distribuídos em todo território nacional, na região Sudeste em maior proporção (54,2\%), seguida pelas regiões Nordeste (16,4\%), Centro-Oeste (12,2\%), Sul (11,8\%) e Norte (5,5\%) (ABRAF, 2014). Sendo, Eucalyptus grandis, Eucalyptus saligna, Eucalyptus urophylla, Eucalyptus viminalis, híbridos de E. grandis x E. urophylla e Eucalyptus dunniias as mais implantadas (EMBRAPA, 2019).

O eucalipto foi introduzido no país em 1904, pelo pesquisador Edmundo Navarro de Andrade que estudou a espécie a fim de tornar viável o plantio do eucalipto em grande escala (Martini, 2010). Essa espécie teve uma grande aceitação no Brasil, visto as grandes áreas ocupadas por ela.

Essa aceitação e crescimento acelerado do eucalipto por todas as regiões do país se dão pelo seu rápido crescimento, alta produtividade, seus múltiplos produtos (papel, celulose, móveis, painéis de madeira, pisos, carvão, construção civil) e também está relacionado com os lucros gerados pelo mesmo. Dados divulgados pelo IBÁ (2020) indicam uma receita bruta de R \$ 97,4 bilhões gerada por florestas plantadas, sendo o eucalipto responsável por grande parte desse valor, apresentando um crescimento de $12,6 \%$ em relação ao ano anterior.

Embora os plantios de eucalipto desde o início tenham sido implantados por conta desses benefícios econômicos, há vários aspectos ambientais oferecidos, como a proteção das matas nativas contra a supressão tendo em vista que são mais de sete milhões de hectares de áreas reflorestadas com eucalipto destinadas à industrias e produção de subprodutos que seriam obtidos das florestas nativas. (Sociedade Nacional de Agricultura, 2017).

O eucalipto também é eficiente na proteção do solo e da água. Quando chove, a vegetação, através da copa, evita o impacto direto das gotas de chuvas no solo protegendo-o contra erosões e consequentemente também protegendo recursos hídricos próximos já que as partículas de solo do processo de erosão são carregadas pela enxurrada e são depositadas nos rios, córregos e lagos provocando assoreamento dos mesmos (Cândido et al., 2014). Outro recurso importante é a fixação de $\mathrm{CO}_{2}$, um hectare com plantio de eucalipto pode estocar 184 toneladas no ciclo de sete anos (Lelis, 2019).

Nesse ínterim, esse estudo faz-se necessário para melhor compreensão e avaliação dos benefícios ambientais do plantio 
de eucalipto uma vez que são poucos os estudos sobre o assunto e existem muitos mitos contra o plantio de eucalipto. Com isso, o objetivo da pesquisa é salientar os impactos ambientais positivos de plantios de eucalipto observando sua influência sobre o solo, água, proteção de florestas nativas, ciclagem de nutrientes e fixação de carbono.

\section{Metodologia}

Foi realizada uma revisão narrativa de literatura, relacionada aos benefícios ambientais do plantio de Eucalipto. Segundo Lakatos e Marconi (2010), a finalidade da pesquisa bibliográfica é colocar o pesquisador em contato direto com tudo o que foi já estudado, escrito e publicado sobre um tema específico. Já revisão narrativa é um método amplo que descreve e busca discutir o desenvolvimento de um determinado assunto sob um ponto de vista teórico ou contextual. Tendo como palavras chaves: Eucalipto; Benefícios Ambientais; Florestas plantadas.

Como critério de inclusão, foram considerados artigos científicos disponíveis online no periódico Capes Google Acadêmico, revistas nos idiomas: português, espanhol, inglês. Além disso, os estudos escolhidos deveriam apresentar as seguintes condições:

Abordagem sobre o histórico do eucalipto;

Apresentar os benefícios do plantio;

Apresentar informações ao leitor sobre os fatores: solo, água, ar e nutrientes;

Abordar sobre a retenção do $\mathrm{CO}_{2}$;

Abertura de mais oportunidades para estudo dos demais plantios de florestas plantadas e seus benefícios.

Para cada artigo foram elencados a população de estudo, bem como sua importância ambiental e ecológica como também a evolução das pesquisas com esse tema.

\section{Resultados e Discussão}

\subsection{Proteção do solo e da água}

As florestas de eucalipto são protagonistas de grandes discussões quando o assunto são impactos ambientais. Os principais tópicos dessas discussões são os efeitos sobre o solo e a água. Diversos mitos afirmam que eucalipto provoca erosões e empobrecimento do solo tornando-o, infértil e que secam toda água disponível que estiver no solo. O solo e a água são recursos naturais renováveis de grande importância para as plantações. O solo é o responsável pela sustentação e por disponibilizar água e nutrientes às plantas. E a água é imprescindível para o crescimento e desenvolvimento das mesmas.

Lima (1996), afirma que o cultivo de eucalipto, em geral, promove resultados benéficos nos atributos químicos do solo como: serapilheira, ciclagem de nutrientes e matéria orgânica. Viana (2004), também relata que plantações florestais de rápido crescimento podem auxiliar fisicamente e quimicamente na recuperação de áreas degradadas ou áreas com mau uso do solo, como amparo para práticas de controle de erosões.

Nesse ínterim, para preservação do solo e da água é imprescindível que toda plantação de eucalipto seja manejada e conservada de forma correta. Manejar o solo é utilizá-lo de forma correta, com relação à fertilização, rotação de cultura e cultivo adequado. Já a conservação do solo está ligada com a designação coletiva dos programas de prevenção e controle à erosão (Modesto Junior \& Alves, 2016).

É correto afirmar então que o plantio de eucalipto protege o solo contra erosões hídricas. Dechen et al. (2015) define erosão hídrica como sendo um fenômeno natural, que, em âmbitos econômicos, é uma das principais formas de degradação dos solos tropicais, acarretando vários prejuízos ambientais e sócio econômicos. Nesse contexto, o plantio de eucalipto protege o solo contra os impactos da gota da chuva, evitando dessa forma uma erosão.

Essa proteção ocorre através da interceptação, que é o processo pelo qual a água da chuva é temporariamente retida 
pelas copas das árvores, nesse caso do eucalipto, sendo o mesmo responsável por interceptar uma boa parte da água da chuva evitando com que as gotas de água caiam diretamente sobre o chão.

Pires et al. (2006) avaliando diferentes sistemas de manejo de uma floresta de eucalipto (eucalipto em nível - EN, eucalipto em desnível - ED e eucalipto em desnível com queima - EDQ), observaram que todos os sistemas de manejo de eucalipto apresentaram perdas de solo muito inferiores ao valor limite de tolerância (11.220 kg.ha-1.ano ${ }^{-1}$ no LV/ Latossolo Vermelho). Costa et al. (2016), através de um estudo onde foram selecionados 10 eventos com maiores intensidades de precipitação para o período avaliado e através de coletas de amostras dos solos observou que na área cultivada com eucalipto, havia uma menor tendência à desagregação/erosão.

Martins et al. (2010), através de um estudo onde objetivou quantificar as perdas de solo e água por erosão hídrica em floresta de produção de eucalipto, em mata nativa (Mata Atlântica) e em solo preparado convencionalmente e mantido descoberto. Teve como conclusão que as perdas de solo para a cultura do eucalipto foram bem abaixo dos limites de tolerância admissíveis para os solos referentes a cada classe. Tais perdas de solo ficaram relativamente próximas daquelas no sistema natural, indicando a sustentabilidade dos plantios de eucalipto, corroborando a importância do eucalipto na proteção dos solos.

Outro fator relevante de estudo é em relação à água, há estudos que comprovam que o eucalipto consome menos água que muitos outros cultivos. Conforme Mendes \& Anderle (2014), a prática da silvicultura para implantação e restauração de florestas procura proveito e preservação racional dos ecossistemas em favor do benefício ecológico, científico, econômico e social. Ainda nesse contexto, o relatório IBÁ, (2015), assegura que não são as plantações florestais em si a causa de possíveis impactos hidrológicos, mas sim as ações mal planejadas de manejo. Para isso existem tecnologias e manejos florestais que devem e necessitam serem empregados como forma de combater os efeitos negativos das perdas de solo em razão da erosão hídrica (Cândido et al., 2014).

Targa et al. (2017), através do seu estudo afirma que a área de mata nativa teve maior capacidade de armazenamento ( $88 \%$ do máximo) de água no solo do que a área de eucalipto (64\% do máximo) nas três profundidades ( 0 - 20 camadas de $\mathrm{cm}$; 20-60 cm e 60- $120 \mathrm{~cm}$ ), durante o período de estudo. Corroborando com os outros autores que afirmam que o eucalipto consome menos água quando comparado com outros plantios, e por fim, não seca o solo.

\subsection{A ciclagem dos nutrientes realizada pela floresta de Eucalipto}

A ciclagem de nutrientes, também conhecida como ciclo biogeoquímico está relacionada com a movimentação dos nutrientes, nos diferentes compartimentos do ecossistema (Souza et al., 2018). Ao saber o que é a ciclagem de nutrientes, é necessário entender também outro fator relevante e de grande importância que é a serrapilheira.

A serapilheira é composta por vegetais em decomposição depositados na superfície do solo, mas seu principal componente são as folhas, contribuindo com até 70\% do material adicionado (Carvalho et al., 2017). Nunes et al. (2012), ainda sustenta que a serrapilheira é a faixa de resíduos que se acumulam sobre o solo dos ecossistemas florestais, sendo este conceito bastante antigo.

Diante disso, a decomposição da serrapilheira regula o acúmulo da matéria orgânica no solo e a ciclagem de nutrientes, atuando no papel imprescindível da manutenção dos ecossistemas florestais (Oliveira et al., 2020). Ao ser decomposta, gera o acúmulo de matéria orgânica na superfície do solo (Barbosa et al., 2017).

De acordo com Carvalho et al. (2017), a serrapilheira encontrada nas plantações de eucalipto é de grande importância na ciclagem de nutrientes, pois contribui para estabilização dos processos erosivos, recuperação de vegetação original e manutenção da sustentabilidade dos ecossistemas e de florestas naturais. Podem levar de um a três anos para se decomporem (Andrade et al., 2003). A quantidade de serrapilheira, biomassa e nutrientes encontradas no solo, são importantes para entender a estrutura do ecossistema e definição da sustentabilidade do ecossistema florestal (Lima, 1996; Spangenberg et al., 1996). 
Foelkel (2005), afirma que estudos têm revelado que os plantios de eucalipto retornam para o solo e para a floresta entre $60 \%$ a $70 \%$ do nitrogênio absorvido do solo, entre $35 \%$ a $60 \%$ do fósforo, entre $55 \%$ a $80 \%$ do potássio, entre $40 \%$ a $60 \%$ do cálcio e 55\% a 70\% do magnésio. Dessa forma, através dos dados citados, outro mito se desfaz quando afirmam que o plantio de eucalipto empobrece o solo, mostrando os benefícios do eucalipto para a natureza, ao invés de fatores negativos, o mesmo traz vários fatores benefícios no meio onde sua cultura é implantada.

\subsection{A conservação das florestas nativas}

De todo consumo de madeira 300 milhões de $\mathrm{m}^{3}$. noo $^{-1}$ referem-se ao consumo de florestas nativas e plantadas para todos os fins, e 100 milhões de m3/ano, a florestas plantadas para uso industrial (Juvenal \&Mattos, 2002). De acordo com a Empresa de Pesquisa Energética (EPE), o consumo de carvão vegetal no setor de cresceu 3,7\% em 2019, chegando a 5,3 milhões de toneladas.

A Figura 1 mostra o consumo de madeiras em toras no Brasil em milhões por metros cúbicos divididos entre florestas nativas na cor azul e florestas plantadas em cor roxa, evidenciando que as florestas plantadas são as mais usadas na produção de celulose e papel, carvão vegetal, entre outros. Nesse contexto, o reflorestamento com espécies exóticas, como o eucalipto, veio contribuir no sentido de reduzir taxas de desmatamento de florestas nativas (BAENA, 2005). Pois usando madeira de florestas plantadas, as madeiras oriundas de florestas nativas são preservadas.

Figura 1. Consumo de madeiras em toras no Brasil.

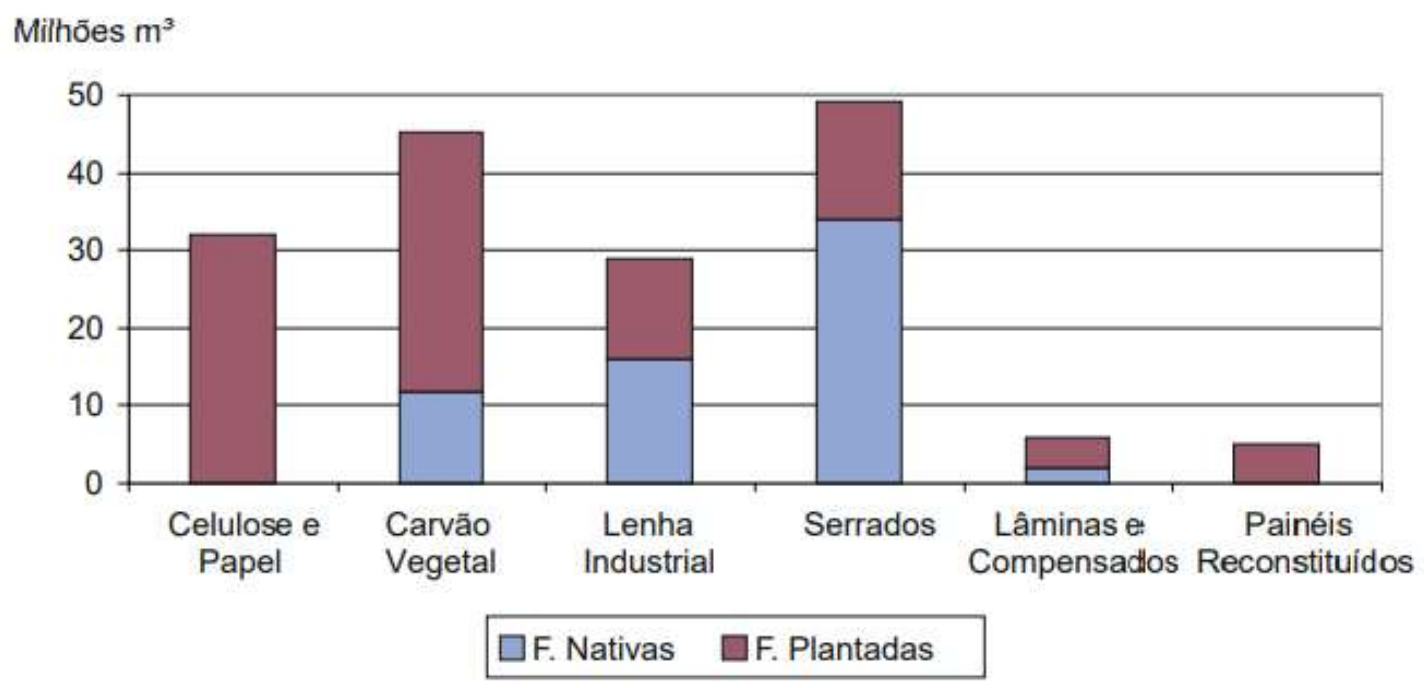

Fonte: Juvenal e Mattos (2002).

De acordo com o Serviço Florestal Brasileiro (SFB), haverá uma queda no fornecimento de madeira de florestas nativas e aumento da demanda do mercado. Dessa maneira, a criação de florestas plantadas além de atender uma grande demanda, reduzem a pressão das matas nativas, diminuindo dessa forma a necessidade de extração de árvores nativas centenárias que servem de abrigo para diversas espécies (IBF, 2009).

A maioria dessas áreas são destinadas para conservação, atividades de monitoramento, restauração, pesquisa científica, educação ambiental e envolvimento da comunidade local, esses são alguns exemplos de como o setor de florestas plantadas atua em prol da biodiversidade. Dessa forma, florestas exóticas, como as de mogno africano, Pinus, Eucalipto, são usadas pela indústria e surgem como uma oportunidade de negócio sustentável. Também garantem a recuperação de áreas de florestas naturais, através dos viveiros que podem atuar em conjunto com as florestas nativas na recuperação de áreas degradadas. 


\subsection{Retenção de $\mathrm{CO}_{2}$ pelo plantio de Eucalipto}

O carbono possui circulação fechada e interconectada por cinco principais reservatórios: oceânico (38.000 Pg), geológico (4.130 Pg), pedológico (2.500 Pg), biótico (560 Pg) e atmosférico (760 Pg) (Carvalho et al., 2010; Lal, 2008). Apesar de representarem os maiores reservatórios de $\mathrm{C}$ no globo terrestre, o carbono fixado nos oceanos, rochas sedimentares e combustíveis fósseis só retorna à atmosfera na escala de séculos e milênios, por meio de vulcanismo, erosão ou extração, conhecido assim como o ciclo lento do carbono (Silva, 2005).

Em contrapartida, o fluxo de $\mathrm{C}$ entre o solo, biosfera e a atmosfera formam o que se chama de ciclo rápido do carbono, responsável pelas mudanças climáticas (Silva, 2005), conduzido principalmente por dois processos biológicos: a decomposição de resíduos orgânicos e a respiração de organismos e do sistema radicular das plantas (Carvalho et al., 2010).

A retirada de $\mathrm{CO}_{2}$ da atmosfera tem sido denominada "sequestro de carbono". Uma vez que o $\mathrm{CO}_{2}$ é um dos principais gases de efeito estufa, as plantações florestais funcionariam como sumidouros, consistindo numa forma de combater o aquecimento global.

Segundo Di Vita et al. (2017), o sequestro ou absorção de carbono é um processo natural que ocorre por meio da fotossíntese durante a fase de crescimento das árvores, que absorvem o dióxido de carbono $\left(\mathrm{CO}_{2}\right)$ do ar e devolvem oxigênio para a atmosfera durante seu crescimento. Com base nessa afirmação, a National Confederation OfIndustry (2012), afirma que quando comparada as florestas nativas e florestas plantadas, essa última se mostra mais eficiente na captura de $\mathrm{CO}_{2}$, visto que seu ciclo dura em média 7 anos, no caso do eucalipto e quanto mais nova a planta, maior necessidade de energia para crescer, no que implica no aumento pela absorção de carbono.

Foi pensando na retenção de $\mathrm{CO}_{2}$ que surgiu o Protocolo de Quioto. Em 1997, no Japão, criou-se o conceito de crédito de carbono, em que, inicialmente, tinha como meta reduzir a emissão de GEEs (Gases de efeitos estufa) em 5\% em relação aos níveis existentes no ano de 1991 (Borges et al., 2016).

O crédito de carbono está relacionado com uma certificação eletrônica emitida quando ocorre uma redução comprovada das emissões de gases, lançados na atmosfera pelas indústrias. Esses créditos são quantificados na proporção de um Crédito de Carbono - equivale a uma tonelada de dióxido de carbono que deixou de ser emitida na atmosfera - referenciando-se em cotas (Borges et al., 2016).

De acordo com o BNDES (2012) as florestas fixam carbono durante seu crescimento armazenando-o como constituinte de suas partes. As florestas plantadas o fazem mais eficientemente, pois são mantidas em pé no seu período de maior crescimento, quando, além do carbono usado para se alimentar, elas fixam a substância na forma de madeira. Gatto et al. (2010), ainda afirma que as plantações de eucalipto constituem opção efetiva de captura de $\mathrm{C}$ e podem imobilizar pelo menos 50 t.ha ${ }^{1}$.ano ${ }^{1}$ de $\mathrm{CO}_{2}$ da atmosfera.

Na Tabela 1, fica bem claro que no Brasil a produção média de florestas é maior quando comparada com os outros países, e como consequência disso o carbono fixado por essas florestas também é maior, em função da quantidade de árvores plantadas em metros cúbicos por hectare/ano. 
Tabela 1. Produção média de florestas e carbono fixado.

\begin{tabular}{lcc}
\hline PAises & $\begin{array}{c}\text { PRODUTIVIDADE } \\
\left(\mathrm{m}^{3} / \mathrm{ha} / \mathrm{ano}\right)\end{array}$ & $\begin{array}{c}\text { CARBONO FIXADO } \\
\text { (t C/ha/ano) }\end{array}$ \\
\hline Folhosas & 30 & 9,2 \\
Brasil & 18 & 4,4 \\
África do Sul & 15 & 3,5 \\
Estados Unidos (Sul) & 12 & 2,9 \\
Portugal & 5,5 & 1,4 \\
Suécia & & \\
Coniferas & 25 & 7,0 \\
Brasil & 22 & 5,4 \\
Chile & 10 & 2,5 \\
Estados Unidos (Sul) & 3,5 & 0,8 \\
Suécia & 2,5 & 0,6 \\
Canadá & & \\
\hline
\end{tabular}

Fonte: Juvenal e Mattos (2002).

Estudo realizado por Vital (2007), baseado em um inventário de E. grandis com seis anos de idade, em Viçosa (MG), verificou-se que o carbono é estocado pela parte aérea, raízes e manta orgânica, sendo a parte aérea a maior fixadora. Lima et.al. (2008), afirmaram que o cultivo do eucalipto em áreas antes ocupadas com pastagens mal manejadas promoveu a recuperação nos estoques de COT (Carbono Orgânico Total). Além das remoções e estoques de carbono nas florestas, o setor também contribui evitando emissões por meio do uso de produtos de origem florestal, ao invés de fontes não renováveis, a exemplo da geração de energia limpa (IBÁ, 2020).

\section{Considerações Finais}

É evidente a necessidade da divulgação dos benefícios trazidos pelas florestas plantadas. Comparando o eucalipto com culturas agrícolas e florestais foi constatado que seu plantio é o que menos consume água e retém nutrientes.

Verificou-se consenso na literatura acerca dos benefícios do plantio do eucalipto sobre o solo protegendo contra erosões hídricas, proteção de matas nativas e da retenção de grandes quantidades de $\mathrm{CO}_{2}$ da atmosfera melhorando a qualidade do ar.

Por ser uma atividade em alta que continua a crescer, e apresenta uma relação direta com o meio ambiente, é importante instigar os estudos sobre os impactos positivos e negativos a logo prazo.

\section{Referências}

ABRAF - Associação Brasileira de Produtores de Florestas Plantadas. (2013). Anuário estatístico da ABRAF 2012: ano base 2011.

Andrade, A. G., Tavares, S. R. L., \& Coutinho, H. L. C. (2003). Contribuição da serapilheira para recuperação de áreas degradadas e para manutenção da sustentabilidade de sistemas agroecológicos. Informe agropecuário, 24 (220), 55-63.

Baena, E. S. (2005). A rentabilidade econômica da cultura do eucalipto e sua contribuição ao agronegócio brasileiro. Conhecimento Interativo. 1 (1), 3 9 .

Barbosa, V., Barreto-Garcia, P., Gama-Rodrigues, E., \& Paula, A. D. (2017). Biomassa, carbono e nitrogênio na serapilheira acumulada de florestas plantadas e nativa. Floresta e Ambiente, 24, 1-9.

Borges, M. S., Borges, K. C. A. S., \& Souza, S. C. A. (2016). Considerações sobre as linhas de Crédito de Carbono no Brasil. Revista Direito Ambiental e Sociedade, 6(2). 137-155.

Cândido, B. M., Silva, M. L. N., Curi, N., \& Batista, P. V. G. (2014). Erosão hídrica pós-plantio em florestas de eucalipto na bacia do rio Paraná, no leste do 
Mato Grosso do Sul. Revista Brasileira de Ciência do Solo, 38, 5, 1565-1575.

Carvalho, D. C., Pereira, M. G. G., Toledo, L. O., Simon, C. A., Rodrigues, J. S., Fernandes, J. C. F., \& Neto, E. C. S. (2017). Ciclagem de nutrientes de um plantio de eucalipto em regeneração de espécies nativas no sub-bosque. Revista Floresta, 47(1), 17-28. Doi: http://dx.doi.org/10.5380/rf.v47i1.43652.

Carvalho, J. L. N., Avanzi, J. C., Silva, M. L. N., Mello, C. R. D., \& Cerri, C. E. P. (2010). Potencial de sequestro de carbono em diferentes biomas do Brasil. Revista Brasileira de Ciência do Solo, 34, 277-290. Doi: https://doi.org/10.1590/S0100-06832010000200001.

Costa, C. D. O., Alves, M. C., Sousa, A. P., Silva, H. R., González, A. P., \& Avalos, J. M. M. (2016). Produção e deposição de sedimentos em uma sub-bacia hidrográfica com solos suscetíveis à erosão. Irriga, 21(2), 284-299. Doi: https://doi.org/10.15809/irriga.2016v21n2p284-299.

Dechen, S. C. F., Telles, T. S., Guimarães, M. D. F., \& Maria, I. C. D. (2015). Perdas e custos associados à erosão hídrica em função de taxas de cobertura do solo. Bragantia, 74, 224-233. Doi: https://doi.org/10.1590/1678-4499.0363.

Di Vita, G., Pilato, M., Pecorino, B., Brun, F., \& D’Amico, M. (2017). A review of the role of vegetal ecosystems in CO2 capture. Sustainability, 9(10), 1840. Doi: https://doi.org/10.3390/su9101840.

EMBRAPA. Perguntas e Respostas - Portal Embrapa. (2019). Embrapa.br. https://www.embrapa.br/pt/web/portal/florestas/transferencia-detecnologia/eucalipto/perguntas-e-respostas.

Foelkel, C. (2005). Minerais e nutrientes das árvores dos eucaliptos: Aspectos ambientais, fisiológicos, silviculturais e industriais acerca dos elementos inorgânicos presentes nas árvores. Eucalyptus Newsletter, 2.

Gatto, A., Barros, N. F. D., Novais, R. F., Silva, I. R. D., Leite, H. G., Leite, F. P., \& Villani, E. M. D. A. (2010). Estoques de carbono no solo e na biomassa em plantações de eucalipto. Revista Brasileira de Ciência do Solo, 34, 1069-1079.

IBÁ - Indústria Brasileira de Árvores. (2015) Relatório Anual Ibá 2015. 100.

IBÁ - Indústria Brasileira de Árvores. (2020). Relatório Anual Ibá 2020.

IBF - Instituto Brasileiro de Florestas. (2009). Quais os benefícios do reflorestamento?. IBF. https://www.ibflorestas.org.br/conteudo/quais-os-beneficios-doreflorestamento.

Juvenal, T. L. \& Mattos, R. L.G. (2002).O setor florestal no Brasil e a importância do reflorestamento. BNDES Setorial, $16,3-30$.

Lakatos, E. M., \& Marconi, M. A.(2010). Fundamentos da metodologia científica. (7a ed.), Atlas, 2010.

Lal, R. (2008). Carbon sequestration. Philosophical Transactions of the Royal Society B: Biological Sciences, 363(1492), 815-830. https://doi.org/10.1098/rstb.2007.2185.

Lelis, A. UFMG (2019). Florestas plantadas de eucalipto sequestram carbono da atmosfera. Universidade Federal de Minas Gerais. https://ufmg.br/comunicacao/noticias/florestas-plantadas-de-eucalipto-sequestram-carbono-da-atmosfera

Lima, A. M. N., Silva, I. R. D., Neves, J. C. L., Novais, R. F. D., Barros, N. F. D., Mendonça, E. D. S., Demolinari, M. S. M. \& Leite, F. P. (2008). Frações da matéria orgânica do solo após três décadas de cultivo de eucalipto no Vale do Rio Doce-MG. Revista Brasileira de Ciência do Solo, 32 , 1053-1063. https://doi.org/10.1590/S0100-06832008000300014.

Lima, W. P. (1996). Impacto ambiental do Eucalipto. (2a ed.), EDUSP,301.

Martini, A. J. (2010). A Introdução do Eucalipto no Brasil Completa 100 Anos. Blog Tudo Sobre Plantas; blog Tudo Sobre Plantas. https://tudosobreplantas.wordpress.com/2010/10/25/a-introducao-do-eucalipto-no-brasil-completa-100-anos/.

Martins, S. G., Silva, M. L. N., Avanzi, J. C., Curi, N., \& Fonseca, S. (2010). Fator cobertura e manejo do solo e perdas de solo e água em cultivo de eucalipto e em Mata Atlântica nos Tabuleiros Costeiros do estado do Espírito Santo. Scientia Forestalis, 38(87), 517-526.

Mendes, D., \& Anderle, R. J. (2014). Análise da diversificação produtiva da silvicultura em propriedade rural (Bachelor's thesis, Universidade Tecnológica Federal do Paraná).

Modesto Junior, M. D. S., \& Alves, R. N. B. (2016). Cultura da mandioca: aspectos socioeconômicos, melhoramento genético, sistemas de cultivo, manejo de pragas e doenças e agroindústria. Embrapa Amazônia Oriental-Livro científico (ALICE).

National Confederation Of Industry. (2012). Brazilian Pulp and Paper Association. Florest plantations: opportunities and challenges for the brazilian pulp and paper industry on the path of sustainability. Brasília: CNI; National Confederation of Industry; Brazilian Pulp and Paper Association, 57 (Rio+20 Sectorial fascicle).

Nunes, E. N., Anselmo, M. D. G. V., Alves, F. A. L., Holanda, A. E., Rosa, J. H., Alves, C. A. B., Lucena, R. F. P. \& Souto, J. S. (2012). Análise da taxa de decomposição da serrapilheira na Reserva Ecológica Mata do Pau-Ferro, Areia-PB. Revista Gaia Scientia, 6(1), 01-06.

Oliveira, A. M. D., Barreto-Garcia, P. A. B., Novaes, A. B. D., Carvalho, F. F. D., \& Meireles, I. E. D. S. (2020). Decomposição da serapilheira foliar em plantios de bambu, nim indiano e eucalipto. Ciência Florestal, 30, 845-855.

Pires, L. S., Silva, M. L. N., Curi, N., Leite, F. P., \& Brito, L. D. F. (2006). Erosão hídrica pós-plantio em florestas de eucalipto na região centro-leste de Minas Gerais. Pesquisa Agropecuária Brasileira, 41, 687-695.

Silva, M. E. S. (2005). Interação biosfera-atmosfera. In: X Encontro de Geógrafos da América Latina - 20 a 26 de março de 2005 . Anais... do X Encontro de Geógrafos da América Latina - 20 a 26 de março de 2005 - Universidade de São Paulo, 14641-14657. 
Research, Society and Development, v. 10, n. 11, e318101119604, 2021

(CC BY 4.0) | ISSN 2525-3409 | DOI: http://dx.doi.org/10.33448/rsd-v10i11.19604

Spangenberg, A., Grimm, U., da Silva, J. R. S., \& Fölster, H. (1996). Nutrient store and export rates of Eucalyptus urograndis plantations in eastern Amazonia (Jari). Forest ecology and management, 80(1-3), 225-234. https://doi.org/10.1016/0378-1127(95)03615-6.

Sociedade Nacional De Agricultura. Sustentabilidade dos reflorestamentos de eucalipto gera ganhos ambientais e econômicos. (2017). Sociedade Nacional de Agricultura. https://www.sna.agr.br/sustentabilidade-dos-reflorestamentos-de-eucalipto-gera-ganhos-ambientais-e-economicos/.

Souza, M. S., Jardim, A. M. D. R. F., Júnior, G. D. N. A., Silva, J. R. I., Leite, M. L. D. M. V., Teixeira, V. I., \& da Silva, T. G. F. (2018). Ciclagem de nutrientes em ecossistemas de pastagens tropicais. Pubvet, 12, 172.

Targa, M. D. S., Batista, G. T., Almeida, A. A. D. S., Pohl, E., \& Paula, G. R. D. (2017). Evaluation of soil water storage in native forest and eucalyptus areas. Revista Ambiente \& Água, 12, 973-984. https://doi.org/10.4136/ambi-agua.2195.

Viana, M. B. (2004). O eucalipto e os efeitos ambientais do seu plantio em escala. Biblioteca da Câmara dos Deputados. Centro de Documentação e Informação Coordenação de Biblioteca, Brasília-DF.

Vital, M. H. F. (2007). Impacto Ambiental das Florestas de Eucalipto. Revista do BNDES, 14(28), 235-276. 